\title{
Hormonal and Psycho-Emotional Disorders in Women with Psychogenic Amenorrhea
}

\author{
Vadym N. Goncharenko*
}

\author{
Women's health Center, "Feofaniya" Clinical Hospital, 21, Academician Zabolotnogo str., Kyiv, 03143, \\ Ukraine
}

\begin{abstract}
The pathogenetic aspects of stress on reproductive health and fertility of a woman are multi-vector, this is justified by the need for timely diagnosis and the development of new approaches to differentiated treatment of PA.
\end{abstract}

Objective: to determine the characteristics of the hormonal profile, the psycho-emotional state and changes in the bioelectric activity of the brain in women with stress-induced psychogenic amenorrhea (PA).

Material and Methods: The main group included 54 women with PA from 19 to 37 years, the control group - 25 healthy women from 18 to 35 years. Blood plasma FSH, LH, E2, P, Pr, DHEAS, C levels were checked by the immunoenzymatic method, bioelectric activity measurement of the brain - with an electroencephalography, women psychoemotional status - by the Spielberg-Hanin test, statistical data processing was performed using Windows SPSS 11.5. and was carried out by means of standard methods.

Results: Patients were divided on 3 subgroups depend on significant $(\mathrm{p}<0.05)$ Prl or $\mathrm{C}$ or their combination levels increasing. The presence of nonspecific signs of activation of the structures of the brain stem in patients with PA was established by EEG with significantly $(p<0.05)$ higher frequency. The analysis of the psycho-emotional status of women showed a high level of personal and reactive anxiety.

Conclusions: The revealed features of hormonal imbalance and psycho-emotional status in women with PA indicate the necessity of involving adjacent specialists - neurologists and psychotherapists for timely and adequate examination with the appointment of differentiated pathogenetically substantiated treatment.

Keywords: Psychogenic amenorrhea, hormonal profile, psycho-emotional state, bioelectric activity of the brain.

\section{INTRODUCTION}

Life in modern society is full of unpredictable socioeconomic events. Such factors as solution of domestic problems and planning of perspectives make people live in a state of strain of their adaptation resources, which are closely related to psychological and physiological well-being [1].

The constant stress in the life of a modern woman, as an unchanging companion to the growing pace of life and global progress, radically changes the way of her life and reduces the body's resistance. A significant role of the chronic stress in the occurrence of reproductive losses was confirmed on the basis of studies conducted at the turn of the millennia [2-5].

It should be noted that a small dose of stress has a positive effect on the psyche, returns youth and vitality, sharpens the skills to overcome the side effects of unpleasant situations. But the real problem is the devastating effects of those stresses, which are called distresses, as they may destroy career, relationships, marriage, health and human life [6].

Address correspondence to this article at the Women's health Center, "Feofaniya" Clinical Hospital, 21, Academician Zabolotnogo str., Kyiv, 03143, Ukraine; Tel: +380442596748; Fax: +380442596955;

E-mail:phdphd509@gmail.com
Therefore, one of the priority goals of the WHO global plan for 2006-2025 [7] is a reduction in the prevalence of illnesses caused by stress. The study of the effects of emotional stress, the development of methods for diagnosis and treatment of pathology caused by stress, including disorders of the female reproductive system, is a trend of modern medical science $[8,9]$.

It is known that the psychological and sociopsychological spheres participate in the realization of the complex system of psychophysiological relations together with integrative cerebral systems and peripheral vegetative-humoral mechanisms, and the effective functioning of this system is one of the prerequisites for optimal physiological support of life during stress reaction $[10,11]$. However, in spite of the non-specificity of the reactions of the organism to the stress-related effect, modern literature pays great attention to the individual-typological peculiarities of the organism's reactions under stress conditions, both personally-psychological and physiological and biochemical, occurring at different levels of the functioning of the organism - organ, tissue, cellular, molecular [12, 13]. At the same time, due to current level of development of scientific technologies, mechanisms of stress are studied at the all levels of structural and functional organization, which allows to 
reveal the deepest processes caused by stress factors [5].

Stress influences largely form the basis for women's reproductive health disorders, since their psychoemotional state is an important component of the state of reproductive health $[14,15]$. The female reproductive system, as the fastest transforming biological object, immediately responds to adverse external and internal factors with the emergence of new adaptation reactions that, under certain conditions, acquire the properties of the pathological process [2].

In modern conditions, the diversity of psychogenic influences is accompanied by an increase in psychoemotional disorders among women and requires the widespread use of clinical and paraclinical methods for determining the mechanisms of central disorders in gynecological diseases [16, 17]. Psychogenic amenorrhea (PA), which manifests itself in the absence of menstruation for six months or more of a variety of mental effects - severe stress and neuropsychic stress [18], is one of the manifestations of stress-dependent menstrual cycle disorder.

In conditions of stress, the cerebral cortex tries to compensate for the severity of psychogenic effects by secreting own (endogenous) substances - opiates that alleviate stressful effects [3, 5, 9]. The isolation of opiates causes cascade changes in hormonal bonds in the hypothalamic-pituitary-adrenal system. There is an increase in the activity of the opioidergic system and the synthesis of endorphins, an increase in the synthesis of corticotropin releasing of the hormone, which causes activation of the adrenal cortex with an increase in the synthesis and secretion of cortisol. As a result, it inhibits the secretion of gonadotropin-releasing hormone, decreases luteinizing and follicle-stimulating hormones [2, 20, 22]. Functional hyperprolactinemia is one of the pathogenic manifestations of the stress reaction of the female body, which further exacerbates the hypothalamic-pituitary dysfunction, reduces the synthesis and secretion of $\mathrm{GnRh}$, breaking the sensitivity of the hypothalamus to estrogens reduces the secretion of progesterone luteum contributes to the suppression of reproductive function in women $[19,21$, 22].

Since the pathogenetic aspects of stress on reproductive health and fertility of a woman are multivector, this is justified by the need for timely diagnosis of PA and the development of new approaches to differentiated treatment of this pathology and is an important trend in modern gynecology.
The goal of the study was to determine the characteristics of the hormonal profile, the psychoemotional state and changes in the bioelectric activity of the brain in women with stress-induced PA.

\section{MATERIAL AND METHODS}

There were investigated 54 women with psychogenic amenorrhea (study group) at the ages from 19 to 37 years and treated in "Feofania" $\mathrm{CH}$ women's health Center (Kyiv, Ukraine) during September 2017 - September 2018. Investigation was performed as a cross-sectional study. The criteria for inclusion to the study were: the post-stress violation of the menstrual function by the type of secondary PA against the background of low or normal levels of gonadotropins. The criteria for exclusion from the study were: the presence of thyroid gland disease, the hormone producing tumors, the uterine form of amenorrhea, body weight deficiency (body mass index less than 18.5) and obesity (body mass index greater than 30). The control group consisted of 25 women at the ages from 18 to 35 years with an unbroken menstrual cycle and unprotected reproductive history.

All exanimated women had signed consent form.

Patients in the main and control groups were examined according to the following scheme: studying the anamnesis data, measuring anthropometric data, conducting general clinical, laboratory and ultrasound examination of the pelvic organs. Blood plasma levels were determined by the immunoenzymatic method of follicle-stimulating hormone (FSH), luteinizing hormone $(\mathrm{LH})$, estradiol (E2), progesterone $(\mathrm{P})$, prolactin $(\mathrm{Prl})$, dihydroepiandrosterone sulfate (DHEAS), cortisol (C) levels. Taking into account the stress-induced genesis of menstrual dysfunction of women, they were examined by neurologist and psychotherapist. The study of bioelectric activity of the brain was performed with an electroencephalography (EEG) using the Nicolet system (USA). Psychoemotional state of women with the definition of personal and reactive anxiety was determined by the Spielberg-Hanin test. Statistical data processing was performed using Windows SPSS 11.5. The assessment of the reliability of the differences in the mean and relative variables was carried out by means of standard methods of variation statistics (Student's t-test, chi-squared test, etc).

\section{RESULTS}

We had investigated hormonal blood plasma content, brain bioelectrical activity features and psycho- 
emotional condition of 54 women with PA from 19 to 37 years (mean age 34.3+_2.2 years). $74.1 \%$ of examined women had university education, $31.8 \%$ had office work, $11.1 \%$-unemployed, $20.4 \%$ - entrepreneur, $37.0 \%$ - public workers. $57.4 \%$ patients were officially married.

We had identified three pathogens of hormone imbalance among women with psychogenic amenorrhea according to it investigated concentrations levels changes in blood plasma.

Primary we had putted attention that among 54 examined patients 24 had same features - isolated increasing level of prolactin (3.6 times, that was significantly, $p<0.05$, higher in comparison with control group) with normal cortisol, follicle-stimulating hormone, luteinizing hormone values. These patients had formatted first subgroup (Table 1).

Then, were found isolated blood plasma cortisol increasing (2.9 times, that was significantly, $p<0.05$, higher in comparison with control group) in another 17 patients (second subgroup) with normal values of $\mathrm{Prl}$, LH and FSH (Table/Figure 1).

And another 13 exanimated patients with psychogenic amenorrhea (third subgroup) had combination of prolactin and cortisol values raise (3.1 times and 4.3 times, that was significantly, $p<0.05$, higher in comparison with control group) (Table 1).

It has been established the reduction of estradiol and progesterone blood plasma levels in all women with psychogenic amenorrhea in comparison with healthy group.
The established peculiarities of hormonal balance disorders among women with PA suggest that the decrease in luteinizing hormone and follicle-stimulating hormone levels with background increase of cortisol and prolactine is the result of increased activity of opioidergic and dopaminergic systems [20, 22]

According to the data that the hypothalamic and extrapolatory brain structures disorder is important for the psychogenic amenorrhea pathogenesis, the functional study of the central nervous system was performed.

The study of bioelectric activity of the brain is carried out in a calm condition of patients. As a result of EEG, the presence of nonspecific signs of activation of the structures of the brain stem in women with PA was established (Table 2).

Were found: signs of epileptiform activity, decrease in amplitude and alpha-rhythm index, the "flashing" high amplitude polymorphic activity domination including rhythms of alpha- and theta-ranges, violation of the regularity and uniformity of the zonal distribution of the basic cortical rhythm. The frequency of all mentioned indexes were significant higher $(p<0.05)$ in patients with psychogenic amenorrhea in comparison with healthy women.

Similar changes were observed in the detection of interhemispheric asymmetry, which were registered 3-6 times more frequently in women of all three subgroups of the main group compared with the control group, who considered the marker of increased mental and emotional stress. The obtained EEG data testify to the signs of activation of the stem structures of the brain in

Table 1: Hormone Profile Indexes for the Examined Patients. Hormone blood plasma content comparison of women in main and control groups. Data shown as mean \pm SEM. The indexes difference is valid (compared to the control group, $p<0,05$ )

\begin{tabular}{|c|c|c|c|c|}
\hline \multirow{2}{*}{$\begin{array}{c}\text { Index } \\
\text { (units of measurement) }\end{array}$} & \multicolumn{3}{|c|}{ Subgroups of the main group } & \multirow{2}{*}{$\begin{array}{l}\text { Control group } \\
\qquad(n=25)\end{array}$} \\
\hline & $\begin{array}{c}1-s t \\
(n=24)\end{array}$ & $\begin{array}{l}2-n d \\
(n=17)\end{array}$ & $\begin{array}{c}\text { 3-rd } \\
(n=13)\end{array}$ & \\
\hline $\operatorname{Prl}(\mathrm{ng} / \mathrm{ml})$ & $61.7 \pm 6.2^{*}$ & $20.8 \pm 2.2$ & $54.2 \pm 5.8^{*}$ & $17.4 \pm 1.8$ \\
\hline DHEAS (mcg/dl) & $162.9 \pm 8.4^{*}$ & $154.2 \pm 6.8$ & $182.7 \pm 9.1^{*}$ & $143.8 \pm 7.2$ \\
\hline LH (ivf/l) & $3.1 \pm 0.2^{*}$ & $3.4 \pm 0.4^{*}$ & $4.2 \pm 0.5^{\star}$ & $8.7 \pm 0.5$ \\
\hline $\mathrm{FSH}$ (ivf/l) & $5.3 \pm 0.4^{*}$ & $6.8 \pm 0.3^{*}$ & $5.1 \pm 0.3^{*}$ & $9.3 \pm 0.6$ \\
\hline $\mathrm{C}(\mathrm{mcg} / \mathrm{dl})$ & $15.6 \pm 1.9$ & $36.2 \pm 2.9^{*}$ & $51.7 \pm 3.4^{*}$ & $12.4 \pm 1.9$ \\
\hline $\mathrm{E} 2(\mathrm{pg} / \mathrm{ml})$ & $54.2 \pm 5.2^{*}$ & $61.6 \pm 4.7^{*}$ & $51.5 \pm 6.1^{*}$ & $87.65 \pm 7.3$ \\
\hline Thyrotropic hormone $(\mathrm{mcU} / \mathrm{ml})$ & $2.1 \pm 0.1$ & $1.7 \pm 0.2$ & $1.6 \pm 0.2$ & $1.7 \pm 0.3$ \\
\hline Progesterone (ng/ml) & $0.9 \pm 0.08^{*}$ & $1.3 \pm 0.09^{*}$ & $0.8 \pm 0.1^{*}$ & $3.2 \pm 0.1$ \\
\hline
\end{tabular}


Table 2: EEG Profile Indexes for the Examined Patients. Encephalography changes frequency among women of main and control groups. Data shown as number and \% of cases. The frequency difference is valid (compared to the control group, $p<0,05$ )

\begin{tabular}{|c|c|c|c|c|}
\hline \multirow[t]{2}{*}{ Index } & \multicolumn{3}{|c|}{ Subgroups of the main group } & \multirow{2}{*}{$\begin{array}{l}\text { Control group } \\
(n=25)\end{array}$} \\
\hline & $\begin{array}{c}1-s t \\
(n=24)\end{array}$ & $\begin{array}{l}\text { 2-nd } \\
(n=17)\end{array}$ & $\begin{array}{c}\text { 3-rd } \\
(n=13)\end{array}$ & \\
\hline Epileptiform activity signs & $\begin{array}{c}3^{*} \\
(12.5 \%)\end{array}$ & $\begin{array}{c}1^{*} \\
(5.8 \%)\end{array}$ & 0 & 0 \\
\hline $\begin{array}{l}\text { The decrease in the amplitude and alpha- } \\
\text { rhythm index }\end{array}$ & $\begin{array}{c}18^{*} \\
(75 \%)\end{array}$ & $\begin{array}{c}15^{*} \\
(88.2 \%)\end{array}$ & $\begin{array}{c}11^{*} \\
(84.6 \%)\end{array}$ & $\begin{array}{c}5 \\
(20 \%)\end{array}$ \\
\hline $\begin{array}{l}\text { The "flashing" high amplitude polymorphic } \\
\text { activity domination including alpha - and theta - } \\
\text { rhythm }\end{array}$ & $\begin{array}{c}6^{*} \\
(25 \%)\end{array}$ & $\begin{array}{c}7^{*} \\
(41.1 \%)\end{array}$ & $\begin{array}{c}4^{*} \\
(30.7 \%)\end{array}$ & $\begin{array}{c}1 \\
(4 \%)\end{array}$ \\
\hline $\begin{array}{l}\text { The violation of the regularity and uniformity of } \\
\text { the zonal distribution of the basic cortical } \\
\text { rhythm }\end{array}$ & $\begin{array}{c}21^{*} \\
(87.5 \%)\end{array}$ & $\begin{array}{c}16^{*} \\
(94.1 \%)\end{array}$ & $\begin{array}{c}10^{*} \\
(76.9 \%)\end{array}$ & $\begin{array}{c}4 \\
(16 \%)\end{array}$ \\
\hline $\begin{array}{l}\text { Extend of the range of reaction of adopting the } \\
\text { rhythm by means of photo stimulation }\end{array}$ & $\begin{array}{c}22^{*} \\
(91.6 \%)\end{array}$ & $\begin{array}{c}15^{\star} \\
(88.2 \%)\end{array}$ & $\begin{array}{c}12^{*} \\
(92.3 \%)\end{array}$ & 0 \\
\hline Signs of the cerebral hemisphere asymmetry & $\begin{array}{c}24^{*} \\
(100 \%)\end{array}$ & $\begin{array}{c}17^{*} \\
(100 \%)\end{array}$ & $\begin{array}{c}13^{*} \\
(100 \%)\end{array}$ & $\begin{array}{c}4 \\
(16 \%)\end{array}$ \\
\hline
\end{tabular}

combination with the signs of interhemispheric asymmetry with predominance of the activity of the right cerebral hemisphere in women with PA.

The analysis of the psycho-emotional status of women, based on the results of the conducted neuropsychological testing using the Spielberg-Hanin anxiety scale, showed a high level of personal and reactive anxiety in the three subgroups of patients with PA in comparison with similar parameters of the control group (Figure 1).

Pathopsychological changes in the examined women from the PA manifested themselves in the form of increasing sanitation, strengthening of individual constitutional anxiety, the stability of dysthymic reactions, lower self-consciousness of their health. The high frequencies of such qualities as jealousy, anxiety, restraint were observed. Evaluation in the points of reactive and personality anxiety showed an increase in 1.5-2.4 times this indicator in three subgroups of women with PA in comparison with the control group.

\section{DISCUSSION}

Psychogenic amenorrhea three pathogenic pathways that were identified in this study, associated with an isolated increase of prolactin, or cortisol, or a combination of these hormones levels in blood plasma, confirm the previously presented theory of the stress

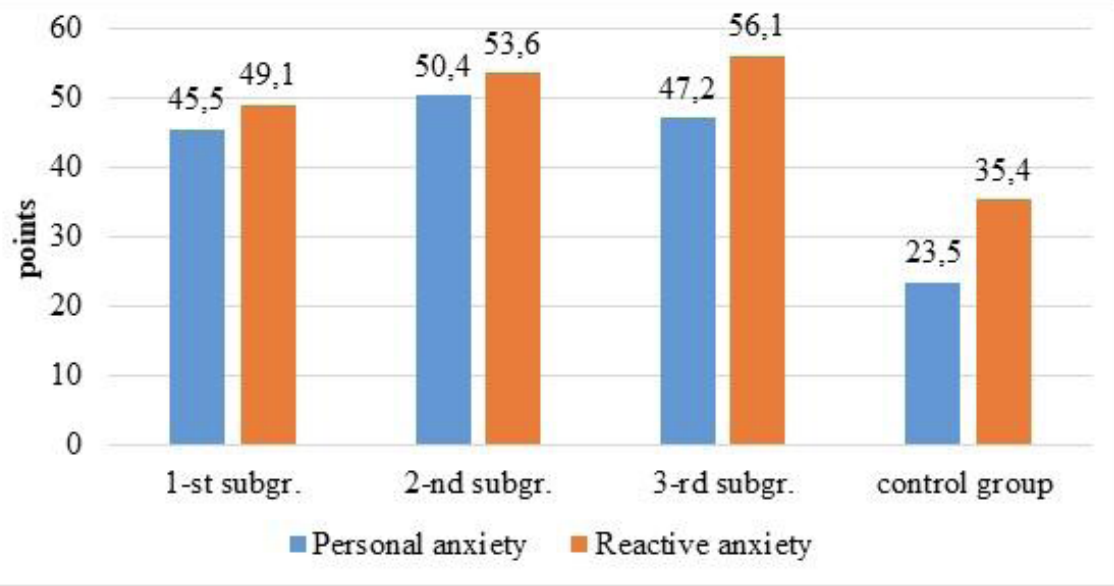

Figure 1: Psychological characteristics of the examined patients on the Spilbega-Hanin scale, points. 
induced secondary amenorrhea development. According to [23] data, when the body is stressed, the hypothalamic-pituitary-adrenal center is activated, which suppresses the hypothalamic-pituitary-gonadal center via corticotropin-releasing hormone inhibiting $\mathrm{GnRH}$ secretion in the hypothalamus. Also, as was reported by [24], corticotropin-releasing hormone inducted $\beta$-endorphins secretion, and on this way $\mathrm{GnRH}$ and dopamine becomes activated. Inhibition of dopamine allows for an increase in prolactin concentration, which leads to inhibition of luteinizing hormone and symptomatically this process manifested as anovulation.

From [25] point of view, females with these condition characteristically have higher levels of testosterone, and lower levels of estrogen, that were also identified in present investigation, and as a result, an increased level of aggression.

However, in our study, we could not only confirm hormonal stress portrait of this pathology, but also to identify specific changes in the brain bioactivity and psycho-emotional status features of patients with psychogenic amenorrhea, witch was significantly differed from healthy women. These findings will be useful for optimizing existing secondary stress induced amenorrhea treatments methods, which is not presented in the current study but will be the task of our future researches (limitation of study).

\section{CONCLUSIONS}

Thus, according to the results of the study, three pathogens of hormone imbalance among women with PA were identified, which should be taken into account in the appointment of further differentiated treatment.

The established increase in the level of prolactin or the combination of increased levels of prolactin and cortisol causes the need for a thorough examination of women to determine the genesis of hyperprolactinemia.

The revealed features of hormonal balance and psycho-emotional status in women with psychogenic amenorrhea indicate the necessity of involving adjacent specialists-neurologists and psychotherapists for timely and adequate examination with the appointment of differentiated pathogenetically substantiated therapy.

\section{REFERENCES}

[1] Pinchuk IYa, Babova KD, Gozhenka Al, Eds. Stress and man: medical and psychological help in stress disorders: manual. Kyiv: Publishing house "Kalita" 2014.
[2] Sudakov KV. Psychoemotional stress: prevention and rehabilitation. Therapeutic Archive 1997; 69(1): 70-74.

[3] Chatterjee A, Chatterjee R. How stress affects female reproduction: An overview. Biomed Res-India 2009; 20(2): 79-83.

https://doi.org/10.4103/0970-938X.54858

[4] Campeau S, Liberzon I, Morilak D, Ressler K. Stress modulation of cognitive and affective processes. Stress 2011; 14(5): 503-19.

https://doi.org/10.3109/10253890.2011.596864

[5] Radley JJ, Kabbaj M, Jacobson L, Heydendael W, Yehuda R, Herman JP. Stress risk factors and stress-related pathology: neuroplasticity, epigenetics and endophenotypes. Stress 2011; 14(5): 481-497. https://doi.org/10.3109/10253890.2011.604751

[6] Maksimenko PD, Koval IA, Maksimenko KS, Papucha MV. Medical psychology. Vinnitsa: Nova Knyga 2008.

[7] World Health Organization. Workers' health: a global plan of action. [Internet]. Geneva: WHO. [cited 2012 Nov 5]. Available from: http://origin.who.int/occupational_health/ WHO_health_assembly_ru_web.pdf

[8] Pshenichnikova MG. The phenomenon of stress. Emotional stress and its role in pathology (continuance). Pathological Physiology and Experimental Therapy 2000; 3: 20-26.

[9] Tatarchuk TF. Stress and reproductive function of women. International Endocrinology Journal 2006; 3(5): 2-9.

[10] Korolchuk MS. Activity psychophysiology. Kyiv: Elga 2004.

[11] Nehoroshkova YuV. Modern medical and biological concept of stress: biology, medicine and psychology (review and our own researches). Actual Problems of Transport Medicine 2012; 1(27): 83-95.

[12] Ilyin EP. Psychology of individual differences. St.-Peterburg: Piter 2004.

[13] Aftanas LI, Reva NV, Savotina LN, Maknev VP. Neurophysiological correlates of induced discrete emotions in humans: an individually oriented analysis. Neuroscience and Behavioral Physiology 2006; 36(2): 119-130.

https://doi.org/10.1007/s11055-005-0170-6

[14] Baibackova UA, Efremova OA, Kojin MI. Psychological and immunologic personality status of patients with neurocirculatory dystonia. Scientific Bulletins of the Belgorod State University. Scientific Bulletins. Medicine. Pharmacy 2011; 13: 29-34.

[15] Venckovskaya IB, Zagorodnyaya AS. Stress-induced disorders of reproductive and sexual function. Reproductive Health. Eastern Europe 2013; 2(26): 113-119.

[16] Lachowsky M, Winaver D. Psychogenic amenorrhea. Gynecol Obstet Fertil 2007; 35(1): 45-48. https://doi.org/10.1016/j.gyobfe.2006.10.032

[17] Pentz I, Nakić Radoš S. Functional hypothalamic amenorrhea and its psychological correlates: a controlled comparison. J Reprod Infant Psychol 2017; 35(2): 137-149. https://doi.org/10.1080/02646838.2016.1278201

[18] Benyuk VO, Makarenko MV, Goncharenko VN. Algorithms in obstetrics and gynecology. Kyiv: TOV "Doctor Media"; 2016.

[19] Tatarchuk TF, Efimenko OA. Modern management of hyperprolactinemia. Health of Woman 2009; 9(45): 33-37.

[20] Ranabir S, Reetu K. Stress and hormones. Indian J Endocr Metab 2011; 15:18-22. https://doi.org/10.4103/2230-8210.77573

[21] Benyuk VA, Girina ON, Usevich IA, Dyndar EA, Nikonyuk TR, Goncharenko VN, Bozhok EN, Liholay PA. Family Doctor's Guide to Obstetrics and Gynecology. Kyiv: TOV "Doctor Media" 2012.

[22] Tatarchuk TF, Bulavenko OV, Tutchenko TN. Optimization of treatment of luteal phase deficiency in women of reproductive age against the background of hyperprolactinemia. Health of woman 2008; 2(34): 72-77. 
[23] Fourman LT, Fazeli PK. Neuroendocrine causes of amenorrhea - an update. J Clin Endocrinol Metab 2015; 100(3): 812-24.

https://doi.org/10.1210/jc.2014-3344

[24] Klein DA, Poth MA. Amenorrhea: an approach to diagnosis and management. Am Fam Physician 2013; 87(11): 781-788.
[25] Sowińska-Przepiera E, Andrysiak-Mamos E, JarząbekBielecka G, Walkowiak A, Osowicz-Korolonek L, Syrenicz M, Kędzia W, Syrenicz A. Functional hypothalamic amenorrhoea - diagnostic challenges, monitoring, and treatment. Endokrynologia Polska 2015; 66(3): 252-260. https://doi.org/10.5603/EP.2015.0033

Received on 22-04-2019

DOI: https://doi.org/10.6000/2292-2598.2019.07.02.1

(C) 2019 Vadym N. Goncharenko; Licensee Lifescience Global.

This is an open access article licensed under the terms of the Creative Commons Attribution Non-Commercial License (http://creativecommons.org/licenses/by-nc/3.0/) which permits unrestricted, non-commercial use, distribution and reproduction in any medium, provided the work is properly cited. 